\title{
Ibuprofen Intervention in Canine Septic Shock: Reduction of Pathophysiology without Decreased Cytokines
}

\author{
Arnold G. Coran, M.D., ${ }^{1}$ Robert A. Drongowski, M.A., Jane J. Paik, B.S., and Daniel G. Remick, M.D. \\ Section of Pediatric Surgery, C. S. Mott Children's Hospital and University of Michigan Medical School, Ann Arbor, Michigan 48109-0245
}

Submitted for publication February 6, 1991

This study was undertaken to evaluate the effect of a cyclooxygenase inhibitor, ibuprofen, at various time intervals in a live Escherichia coli model of canine septic shock. Group I (control) animals $(n=5)$ received a LD100 dose of $10^{9}$ live $E$. coli per kilogram were given no further treatment. Group II animals $(n=5)$ received a $10 \mathrm{mg} / \mathrm{kg}$ bolus of ibuprofen $10 \mathrm{~min}$ prior to bacterial infusion. Group III animals $(n=5)$ received ibuprofen $15 \mathrm{~min}$ after the bacterial infusion. Statistical analysis revealed the following: Group II animals had significantly higher MABP and significantly lower levels of serum fluorescent products (superoxide radical activity), plasma thromboxane $\mathrm{B2}$, prostaglandin $\mathrm{E2}$, and endotoxin levels compared to Group I animals $(P<$ 0.05). Plasma levels of tumor necrosis factor (TNF) and interleukin-6 (IL-6) were significantly elevated $(P<$ 0.05 ) from baseline in all animals (Groups I, II, and III), but ibuprofen treatment failed to either increase or decrease these levels. This study demonstrates that ibuprofen treatment can significantly reverse the deleterious hemodynamic and metabolic effects commonly seen in live $E$. coli septic shock without depressing the endogenous production of TNF or IL-6. These data support the hypothesis that sepsis initiates a cascade of mediators with the cytokines TNF and IL-6 being proximal events which in turn stimulate the next level, with ibuprofen probably exerting its inhibitory effect distal to this point in the cascade. 1992 Academic Press, Inc.

\section{INTRODUCTION}

Gram-negative septic shock remains a major clinical problem with significant associated morbidity and mortality. Oxygen-derived free radicals, which are generated during tissue ischemia via the enzyme xanthine oxidase or from activated neutrophils, have been implicated as mediators of tissue injury via peroxidation of lipid membranes [1] in a wide variety of disease processes including shock $[2,3]$. Prostaglandins, which are derived from the arachidonic acid cascade and which possess a variety

\footnotetext{
${ }^{1}$ To whom reprint requests should be addressed.
}

of vasoactive properties, have been demonstrated to be elevated in experimental models of endotoxin shock [415]. In addition, several investigators have suggested that toxic oxygen metabolites and peroxides are formed during arachidonic acid metabolism [16-19]. Recent attention has focused on the role of the cytokine tumor necrosis factor (TNF) in septic shock [20,21]. Levels of TNF are elevated during septic episodes, and elevated serum levels are predictive of fatal outcome [22]. Furthermore, TNF can directly stimulate neutrophils [23] and arachidonic acid metabolism [24, 25].

Ibuprofen, a nonsteroidal, anti-inflammatory agent, which inhibits cyclooxygenase, has been shown to have beneficial effects in hemorrhagic and endotoxin shock by stabilizing blood pressure, preventing acidosis, and increasing survival $[4,5,26-29]$. It has been demonstrated that administration of cyclooxygenase inhibitors such as aspirin, indomethacin, or ibuprofen eliminates the increase in plasma levels of arachidonic acid derivatives seen in shock and improves survival [27, 30,31].

The precise biochemical mechanisms involved in these protective effects of ibuprofen are likely multifactorial, involving both interference with oxidant injury and inhibition of arachidonic acid metabolite formation. This study was designed to document the metabolic and hemodynamic efficacy of ibuprofen treatment instituted both pre- and postlive Escherichia coli administration in young mongrel puppies and to investigate the role of tumor necrosis factor as a mediator in septic shock.

\section{MATERIALS AND METHODS}

Fifteen mongrel puppies weighing between 2 and $8 \mathrm{~kg}$ were randomly divided into three experimental groups as follows: Group I $(n=5), E$. coli infusion with no further treatment; Group II $(n=5)$, bolus intravenous injection of ibuprofen ${ }^{2}(10 \mathrm{mg} / \mathrm{kg}) 10 \mathrm{~min}$ prior to the bacterial infusion; and Group III $(n=5)$, the same ibuprofen dose $15 \mathrm{~min}$ after completion of the bacterial infusion. On the experimental day, each puppy received

\footnotetext{
${ }^{2}$ Donated by the Upjohn Company, Kalamazoo, Michigan.
} 
a $2.5 \mathrm{mg} / \mathrm{kg}$ dose of xylazine hydrochloride subcutaneously, followed by $20 \mathrm{mg} / \mathrm{kg}$ of intravenous pentobarbitol. The animals were intubated and allowed to respire spontaneously. An orogastric tube was placed for decompression of the stomach. Bilateral femoral artery and vein catherizations were performed for monitoring arterial pressure, sampling blood, and administering the $E$. coli infusion and ibuprofen. In addition, a $5 \mathrm{fr}$. SwanGanz pediatric thermal dilution catheter was introduced into the pulmonary artery via the right femoral vein and connected to a Oximetrix -3 cardiac output monitor for monitoring thermal dilution cardiac output during the course of the experiment.

Cardiac output, mean systemic blood pressure, fluorescent products of lipid peroxidation, prostaglandin $\mathrm{E}_{2}$ $\left(\mathrm{PGE}_{2}\right)$, thromboxane $\mathrm{B}_{2}\left(\mathrm{TBX}_{2}\right)$, 3,4-pamine, epinephrine, norepinephrine, TNF, interleukin-6 (IL-6), and endotoxin levels were measured twice during a $30-\mathrm{min}$ equilibration period prior to infusion of bacteria. An LD100 dose ( $10^{9}$ organisms $/ \mathrm{kg}$ ) of live $E$. coli (Dunwald strain B15:0125) in a saline suspension was then infused into the inferior vena cava over a 10 -min period. The number of organisms was determined by optical density using a Bausch and Lomb Spectronic 88 spectrophotometer at $350 \mathrm{~nm}$. The above parameters were measured again at $15,30,60,90,120$, and $180 \mathrm{~min}$ following bacterial infusion. The total blood volume withdrawn was 80 $\mathrm{ml} / \mathrm{animal}$.

Fluorescent products of lipid peroxidation. Serum levels of fluorescent products of lipid peroxidation were analyzed as follows: $0.5 \mathrm{ml}$ of serum was extracted with 7.0 $\mathrm{ml}$ of warm $\left(45^{\circ} \mathrm{C}\right) 2: 1$ chloroform:methane, vigorously vortexed for $2 \mathrm{~min}$, and then centrifuged for $5 \mathrm{~min}$. Following these steps, $5.0 \mathrm{ml}$ of the lower organic layer was transferred to a clean test tube. Two milliliters of $0.25 \mathrm{~N}$ hydrochloric acid was then added followed by $1 \mathrm{~min}$ of vortexing and $5 \mathrm{~min}$ of centrifugation. The resulting upper layer was then transferred to disposable cuvettes and subsequently read using a Perkin-Elmer LS-50 Luminescence Spectrometer with an excitation setting of 360 $\mathrm{nm}$, slit $10 \mathrm{~nm}$, emmission wavelength $430 \mathrm{~nm}$, slit 20 nm [32].

Tumor necrosis factor. Tumor necrosis factor bioactivity was analyzed using a highly sensitive cell line, WEHI 164, subclone 13 (the generous gift of Dr. Anders Waage, University of Trondheim, Norway). These cells have been shown to be able to detect TNF at a concentration of $2 \mathrm{pg} / \mathrm{ml}$ [33]. We have previously demonstrated that this assay was unaffected by IL-1, IL-2, IL6 , and that there was no synergy between interferon- $\gamma$ and TNF in this assay [34]. Briefly, samples were serially diluted in 96 -well microtiter plates. The WEHI cells were resuspended at $5 \times 10^{4}$ cells $/ \mathrm{ml}$ in RPMI 1640 with $10 \%$ fetal calf serum, $2 \mathrm{mM}$ L-glutamine, and $0.5 \mu \mathrm{g} / \mathrm{ml}$ actinomycin D (Calbiochem, La Jolla, CA). The cells were added to the plates and allowed to incubate over- night at $37^{\circ} \mathrm{C}$. Cell lysis was detected by adding M'I'T'tetrazolium and incubating the plates an additional $4 \mathrm{hr}$. The dark purple tetrazolium salts were then dissolved in acidified isopropanol. Units of TNF were calculated based on a recombinant standard run in the same assay.

Catecholamines. Norepinephrine, epinephrine, and dopamine were measured by high pressure liquid chromatography (HPLC) with electrochemical detection. An internal standard $(1250 \mathrm{pg} / \mathrm{ml}$ dihyroxybenzylamine) was added to each plasma sample. The catecholamines were extracted from the plasma by adsorption to alumina at neutral $\mathrm{pH}$ and subsequently eluted with $0.1 \mathrm{M}$ perchloric acid. The catecholamines were then eluted with aqueous acetonitrile/chloroacetic acid/sodium octyl sulfate $(5 \% / 0.1 \mathrm{M} / 300 \mathrm{mg} / \mathrm{liter})$ by reversed phase HPLC on a heated $\left(35^{\circ} \mathrm{C}\right) \mathrm{C}-18$ column $(0.5$ u Biophase, $25 \times 0.4 \mathrm{~cm}$, Bioanalytical Systems, West Lafayette, IN). They were detected amperometrically with a glassy carbon electrode (LC-4B, Bioanalytical Systems) at 0.65 $\mathrm{V}$. The concentration of each catechol was measured by comparison of the resultant peak heights with those produced by the pure catecholamines and corrected for recovery by reference to the internal standard [35].

Prostaglandin E2. C-18 Sep-Pak cartridges (Waters Associates, Milford, MA) were prewashed with $5.0 \mathrm{ml}$ of methanol followed by $5.0 \mathrm{ml}$ of deionized water. A $1.0-\mathrm{ml}$ plasma sample, to which $\left[{ }^{3} \mathrm{H}\right]$ thromboxane $\mathrm{B}_{2}(0.01 \mu \mathrm{Ci}$; NET-603, New England Nuclear, Boston, MA) was added, was then applied to a C-18 Sep-Pak cartridge. The cartridge was then washed with $20 \%$ methanol (5.0 $\mathrm{ml})$ followed by deionized water $(5.0 \mathrm{ml})$. The prostaglandins were subsequently eluted by two sequential $1.0-\mathrm{ml}$ washes with $80 \%$ methanol. The solvent was evaporated from the extract under a stream of dry air at ambient temperature and the residue dissolved in $0.1 \mathrm{M}$ phosphate-buffered saline containing $0.1 \%$ pigskin gel $(\mathrm{pH}$ 7.4) (PBS-Gel) prior to radioimmunoassay analysis. The recovery of $\left[{ }^{3} \mathrm{H}\right]$ thromboxane $\mathrm{B}_{2}$, monitored by counting a $100-\mu \mathrm{l}$ aliquot of the reconstituted sample, averages $89.6 \pm 4.5(\mathrm{SD}) \%$. Levels of prostaglandin $\mathrm{E}_{2}\left(\left[{ }^{3} \mathrm{H}\right] \mathrm{PgE}_{2}\right)$ were then measured by radioimmunoassay using commercially available antibody (Catalog Number 114010 , Cayman Chemical Co., Ann Arbor, MI) and $\left[{ }^{3} \mathrm{H}\right] \mathrm{PgE}_{2}$ tracer (NET-428, New England Nuclear). The tracer, test sample, antibody, and $400 \mu \mathrm{l}$ PBS-Gel were incubated for $18 \mathrm{hr}$ at $4^{\circ} \mathrm{C}$. The unbound prostaglandin was subsequently absorbed by addition of $1.0 \mathrm{ml}$ of a suspension consisting of $0.25 \%$ activated charcoal (Norit A, Sigma Chemical Co., Kansas City, MO) and 0.025\% Dextran T70 (Pharmacia Fine Chemicals, Uppsala, Sweden) in $0.1 M$ phosphate-buffered saline (PBS), pH 7.4. The supernatant was then mixed with $5.0 \mathrm{ml}$ of scintillation fluid (Ecolume, ICN Biochemicals, Irvine, CA). The $\beta$-radioactivity due to antibody-bound tracer was measured in a liquid scintillation counter (Model 6893, Tm Analytic, Elk Grove Village, IL). The concentration 


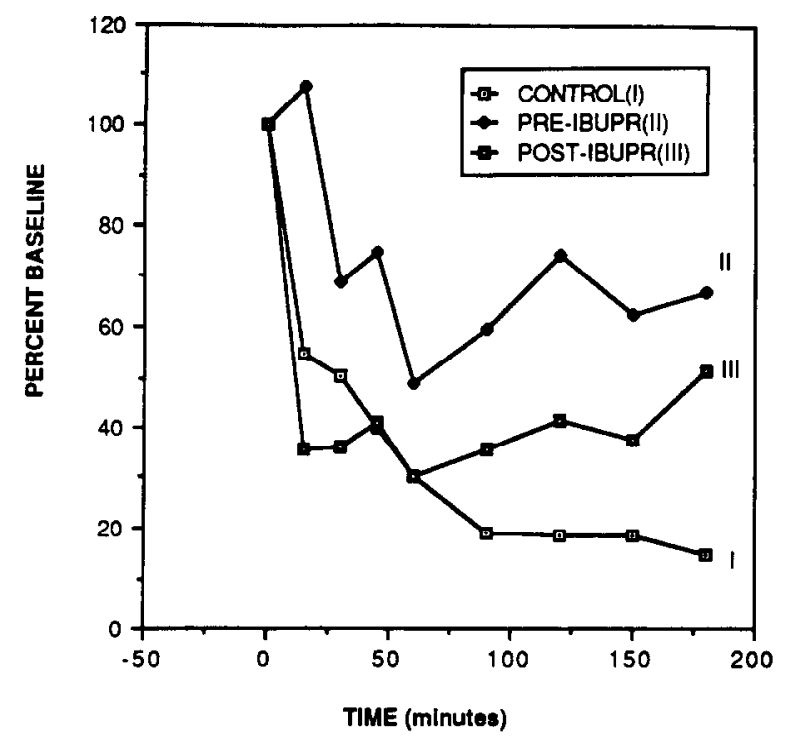

FIG. 1. The cardiac output is expressed as a percentage of the baseline. Each value is the mean of five animals. Although pretreatment with ibuprofen improved cardiac output, this was not significant.

of $\mathrm{PgE}_{2}$ in each sample was determined using a four-parameter logistic curve fit option of an MS-DOS program (Arbor Immunalysis, Ann Arbor, MI) on a Zenith Z-158 PC (Zenith Data Systems, St. Joseph, MI). This assay has a sensitivity of $60 \mathrm{pg} / \mathrm{ml}$ and an interassay coefficient of variation of $14 \%$ [36].

Thromboxane B2. Thromboxane $\mathrm{B}_{2}$ was measured by radioimmunoassay method using commercially available $\left[{ }^{3} \mathrm{H}\right]$ thromboxane $\mathrm{B}_{2}\left(\left[{ }^{3} \mathrm{H}\right] \mathrm{TxB}_{2}\right)$ tracer (NET-603, New England Nuclear, Boston, MA), antibody (Fitzpatrick) and a procedure similar to that used for measurement of $\mathrm{PgE} \mathrm{E}_{2}$. The thromboxane $\mathrm{B}_{2}$ assay has a sensitivity of $18 \mathrm{pg} / \mathrm{ml}$ and an interassay coefficient of variation of $9 \%$ [37].

Endotoxin assay. Endotoxin levels were measured by using the Limulus Amebocyte Lysate Test (Whittaker Bioproducts, Inc.). The plasma samples were diluted 1:10 with pyrogen-free water, then heated to $75^{\circ} \mathrm{C}$ for 15 min. Fifty microliters of sample or standard was placed in standard microtiter ELISA plates. Following a fifteen-min incubation at $37^{\circ} \mathrm{C}, 50 \mu \mathrm{l}$ of limulus amebocyte lysate was added to each well, followed by an additional 30-min incubation. One hundred microliters of chromogenic substrate solution was added to each well, incubated for $6 \mathrm{~min}$, and the reaction stopped by the addition of $50 \mu \mathrm{l}$ of $25 \%$ acetic acid. The microtiter plates were then analyzed at $405 \mathrm{~nm}$ with a Bio-Tek EL-312 BioKinetics Reader (Winooski, VT).

Interleukin- 6 assay. The IL-6 assay was performed using the B9 cell line, which is very sensitive to IL-6. This assay was performed by placing serial dilutions of the samples into 96-well microtiter plates and then adding $5000 \mathrm{~B} 9$ cells in RPMI 1640 with $2 \mathrm{~m} M$ L-glutamine,
$25 \mathrm{~mm}$ Hepes, $1 \%$ pen/strep, $5 \times 10^{-5} M$ mercaptoethanol, and $10 \%$ fetal calf serum. The cells were incubated for $68 \mathrm{hr}$ at $37^{\circ} \mathrm{C}$ and pulsed for the final $6 \mathrm{hr}$ with MTTtetrazolium. The crystals were dissolved with actified isopropanol, and the units were calculated based upon a standard curve run in the same assay [38].

Data were subjected to statistical analyses as follows: Group I (control, $n=5$ ), Group II (pre-ibuprofen-treated animals, $n=5$ ), and Group III (postbacterial infusion ibuprofen-treated animals, $n=5$ ), Figs. 1-8. The Michigan Interactive Data Analysis System (MIDAS) was used to analyze data by univariate and repeated measures analysis of variance, with $P$ values less than 0.05 considered significant.

\section{RESULTS}

Mean cardiac output. Mean cardiac outputs, expressed as a percentage of baseline levels, are shown in Fig. 1. In Group I (control animals) mean cardiac output dropped to below $60 \%$ of baseline levels and continued to decrease throughout the study period. In contrast, in Group II (prebacteria ibuprofen-treated animals), mean cardiac output dropped to $50 \%$ of baseline levels by 60 min postbacterial infusion and then continued to rise to approximately $70 \%$ of baseline. In Group III (postbacteria ibuprofen-treated animals), mean cardiac output dropped significantly after the bacterial infusion, followed by a gradual increase after administration of the ibuprofen; however, these increases were not statistically significant.

Mean arterial pressure. Mean systemic arterial blood pressure, expressed as a percentage of baseline levels, is depicted in Fig. 2. In the Group I (control) animals, mean arterial pressure decreased throughout the

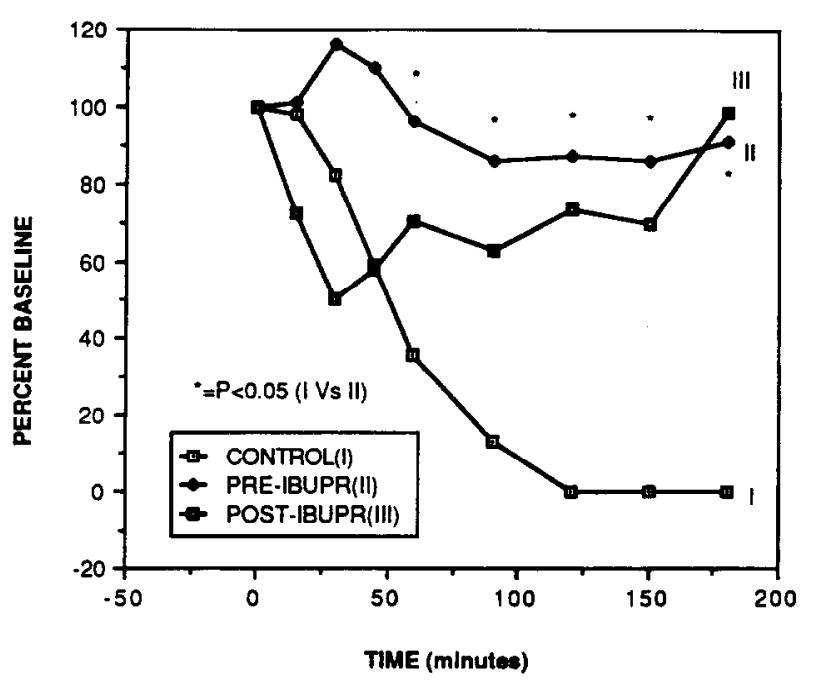

FIG. 2. The mean arterial blood pressure is expressed as a percentage of the baseline. Each value is the mean of five animals. Pretreatment with ibuprofen prevented the drop in blood pressure. 


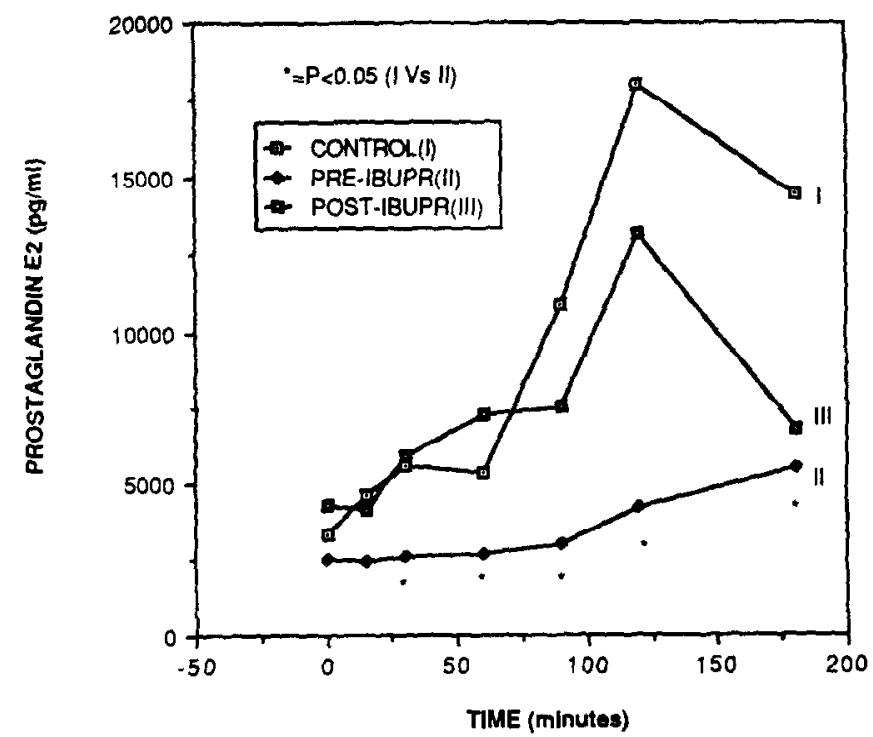

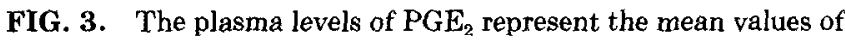
five animals. Pretreatment with ibuprofen prevented the rise in plasma $\mathrm{PGE}_{2}$.

course of the experiment. The mean arterial pressure in the Group II (pretreated) animals was significantly higher than in the control animals, remaining at about $90 \%$ of baseline levels throughout the study period. In the Group III (post-treated) animals, mean arterial pressure decreased to $50 \%$ of baseline following the bacterial infusion and then gradually rose to about $70 \%$ of initial levels following the administration of the ibuprofen.

Prostaglandin. Mean blood prostaglandin $\mathrm{E}_{2}\left(\mathrm{PGE}_{2}\right)$ levels are shown in Fig. 3. The Group II (pretreated) animals experienced significantly decreased levels of $\mathrm{PGE}_{2}$ in comparison with either the Group I (control) or Group III (post-treated) animals, consistent with its potent activity as a cyclooxygenase inhibitor.

Thromboxane. Mean blood Thromboxane $\mathrm{B}_{2}\left(\mathrm{TBX}_{2}\right)$ levels are shown in Fig. 4. The Group II (pretreated) animals have significantly decreased levels of $\mathrm{TBX}_{2}$ compared with the Group I (control) animals. Mean blood Thromboxane $\mathrm{B}_{2}$ levels in the Group III (posttreated) animals were intermediate between the Group I and Group II dogs.

Fluorescent products. Serum levels of fluorescent products of lipid peroxidation were significantly lower in both the pretreated (Group II) and the posttreated (Group III) dogs in comparison with the control (Group I) animals (Fig. 5).

Catecholamines. Plasma catecholamine levels (epinephrine, norepinephrine, and dopamine) are depicted in Table 1. Mean plasma catecholamine levels began to increase significantly $90 \mathrm{~min}$ following the $E$. coli infusion in all three experimental groups. There were no significant between-group differences in mean catecholamine levels during the experiment.

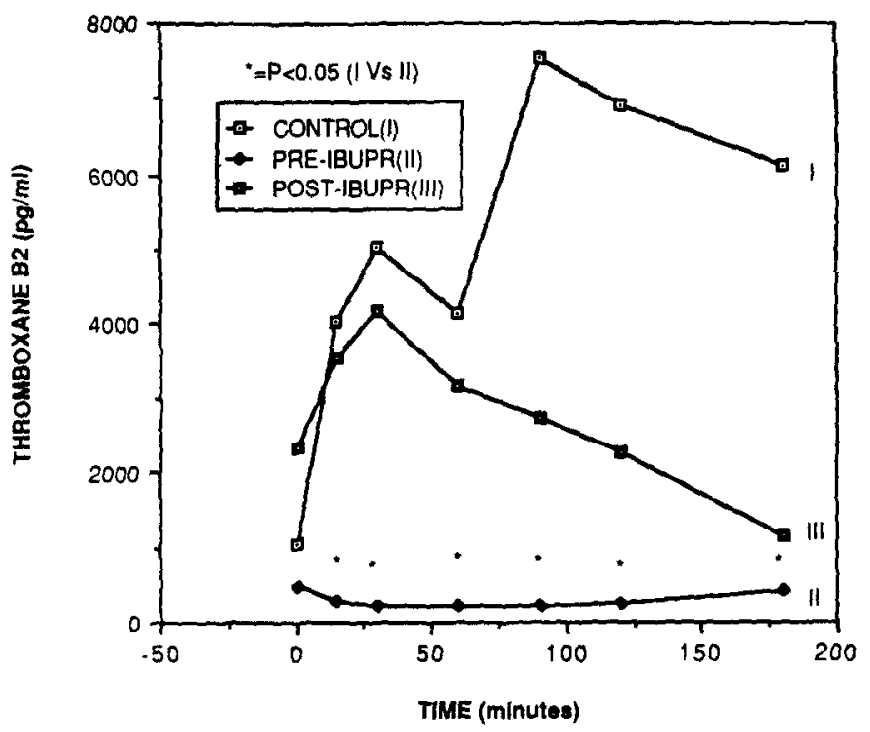

FIG. 4. The plasma levels of $\mathrm{TXB}_{2}$ represent the mean values of five animals. Pretreatment with ibuprofen prevented the rise in plasma $\mathrm{TXB}_{2}$.

Interleukin-6. Mean plasma levels of interleukin- 6 increased significantly from baseline levels 90 min after the bacterial infusion; however, there are no significant between-group differences (Fig. 6). Neither prior or post-treatment with ibuprofen altered the rise in IL-6.

Tumor necrosis factor. Mean levels of tumor necrosis factor increased significantly from baseline 60 minutes after the bacterial infusion and peaked at $2-3 \mathrm{hr}$ in all three groups. There were no significant between-group differences (Fig. 7) Ibuprofen treatment appeared to prevent the characteristic rapid decline in plasma TNF.

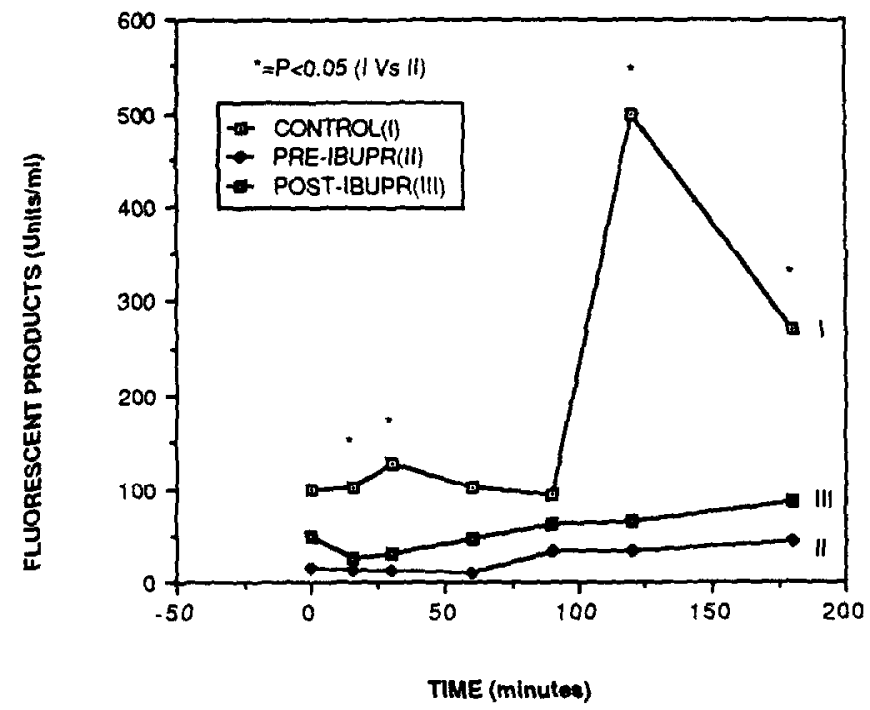

FIG. 5. The plasma levels of fluorescent products represent the mean values of five animals. Pretreatment or post-treatment with ibuprofen prevented the rise in plasma fluorescent products. 


\section{TABLE 1}

Mean Plasma Catecholamine Levels (Epinephrine, Norepinephrine, and Dopamine) during Live $E$. coli Septic Shock in Dogs

\begin{tabular}{rrrr}
\hline Time & $\begin{array}{c}\text { Control } \\
\text { (I) }\end{array}$ & $\begin{array}{c}\text { Pre-ibupr } \\
\text { (II) }\end{array}$ & $\begin{array}{c}\text { Post-ibup } \\
\text { (III) }\end{array}$ \\
\hline \multicolumn{4}{c}{ Epinephrine } \\
0 & \multicolumn{2}{c}{} \\
15 & 82 & 89 & 75 \\
30 & 251 & 133 & 476 \\
60 & 1468 & 245 & 884 \\
90 & 2713 & 412 & 2657 \\
120 & 14608 & 6086 & 28120 \\
180 & 24819 & 10927 & 34475 \\
& 21755 & 31569 & 58380
\end{tabular}

Norepinephrine

$\begin{array}{rrrr}0 & 479 & 303 & 517 \\ 15 & 358 & 355 & 600 \\ 30 & 733 & 370 & 696 \\ 60 & 846 & 863 & 1276 \\ 90 & 5778 & 2064 & 4523 \\ 120 & 7710 & 9809 & 13750 \\ 180 & 9815 & 18575 & 35476\end{array}$

Dopamine

\begin{tabular}{rrrr}
0 & 13 & 13 & 15 \\
15 & 13 & 20 & 14 \\
30 & 21 & 13 & 14 \\
60 & 26 & 40 & 18 \\
90 & 54 & 11 & 15 \\
120 & 164 & 61 & 60 \\
180 & 173 & 112 & 224 \\
\hline
\end{tabular}

Endotoxin. Mean plasma levels of endotoxin are shown in Fig. 8. The Group II (pretreated) animals experienced significantly decreased levels of endotoxin in comparison with the Group I (control) animals.

\section{DISCUSSION}

Several experimental models of septic shock have been used to demonstrate an increase in the circulating levels of the end products of the cyclooxygenase pathway, including $\mathrm{PGE}_{2}[6,39]$ and $\mathrm{TBX}_{2}$ [40]. Given their documented increase during episodes of sepsis, it is reasonable to test the hypothesis that the formation of these potent metabolites may be playing a critical role in the pathogenesis of septic shock. Indeed, previous investigators have also shown that the cyclooxygenase inhibitor, ibuprofen, offers protection against the deleterious hemodynamic effects of septic shock [5, 7, 28]. Our data confirm these previous reports and show that ibuprofen will significantly improve hemodynamic function in animals given a lethal bacterial challenge of $E$. coli. Both cardiac output and mean arterial blood pressure were better maintained with ibuprofen therapy, and prior ad-

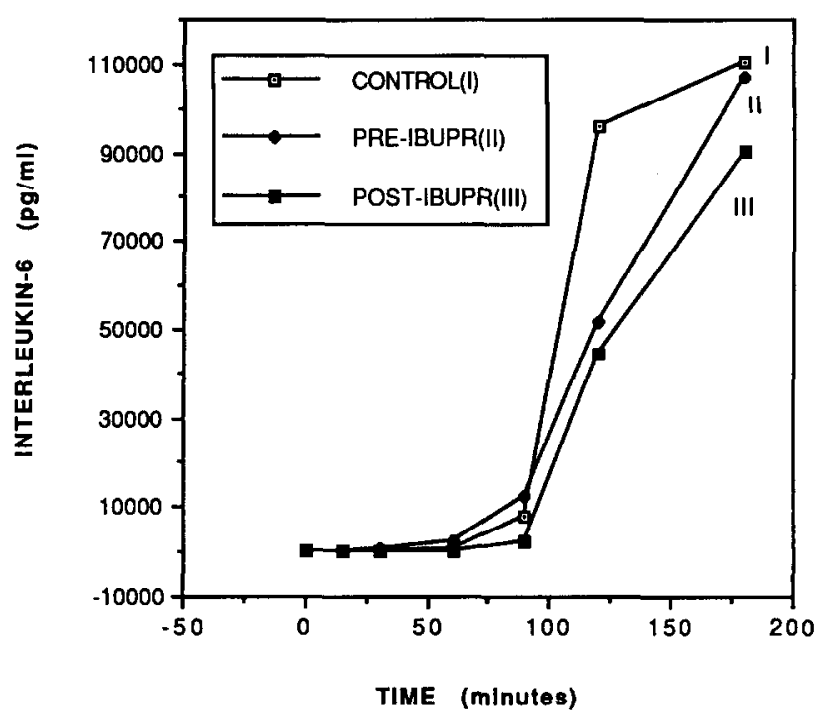

FIG. 6. The plasma IL-6 levels represent the mean values of five animals. IL-6 did not begin to increase until $90 \mathrm{~min}$ after the bacterial infusion. Ibuprofen treatment had no effect on the production of IL-6.

ministration of the drug provided greater protection compared to giving the drug after the bacterial challenge. Pretreatment with ibuprofen prevented the rise in both $\mathrm{PGE}_{2}$ and $\mathrm{TBX}_{2}$ induced by the septic challenge.

Recent studies have focused attention on the role of endogenously produced cytokines on the altered pathophysiology observed in septic shock $[20,21]$. The link between the generation of tumor necrosis factor and septic shock is very strong, and TNF is considered pivotal in the development of septic shock. Data supporting

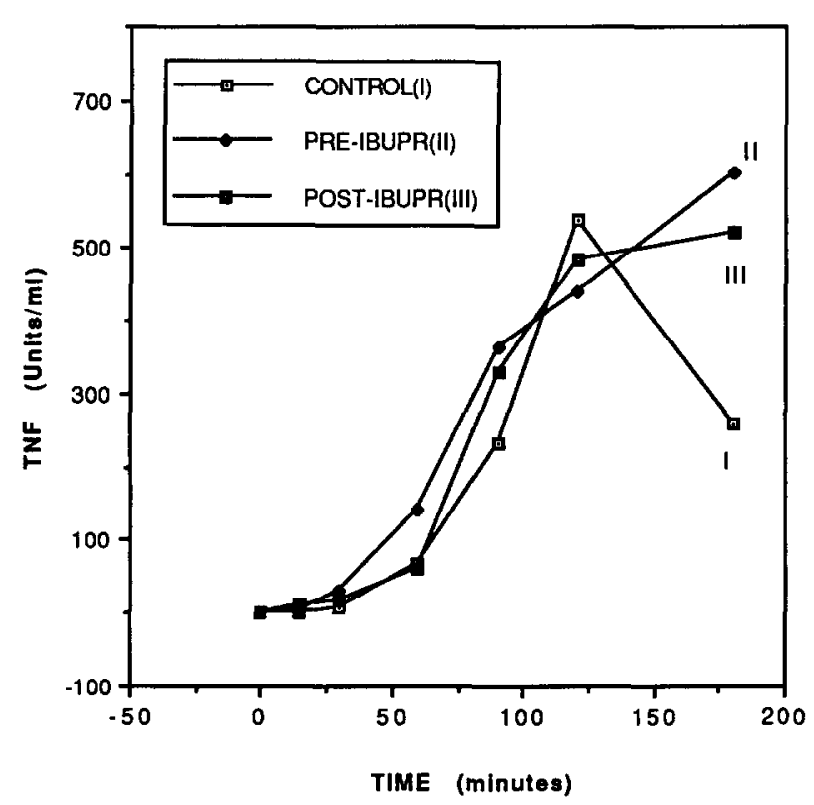

FIG. 7. The plasma TNF levels represent the mean values of five animals. Levels peaked between $2-3 \mathrm{hr}$ after bacterail infusion; ibuprofen had no significant effect over the time period studied. 


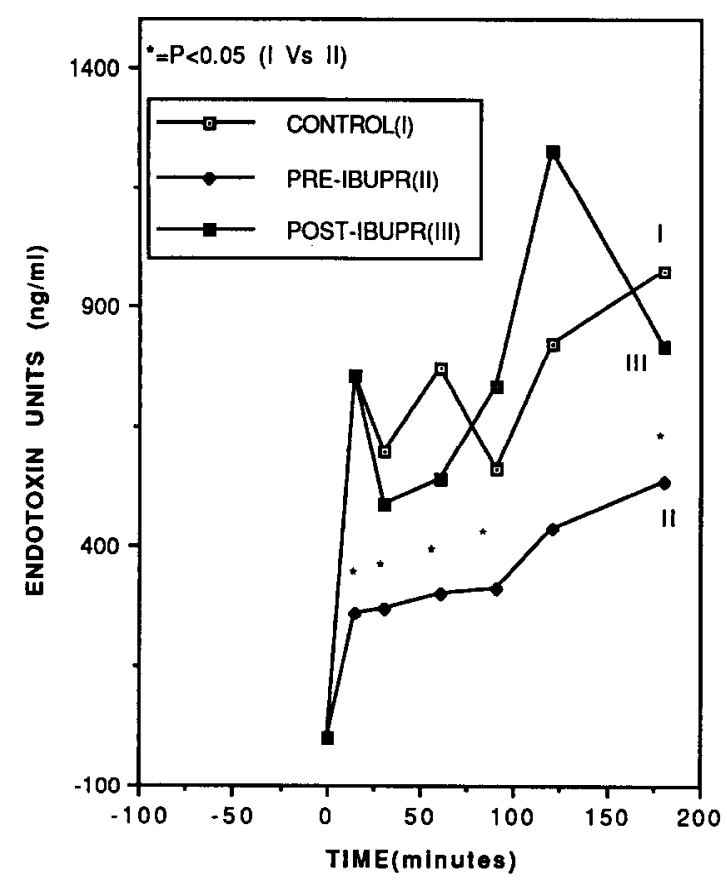

FIG. 8. The plasma levels of endotoxin represent the mean values of five animals. Pretreatment with ibuprofen blunted the increase in plasma endotoxin.

the role of TNF come from several independent investigations. First, plasma levels of TNF are elevated in patients in septic shock [22] or patients in intensive care units $[41,42]$, and the plasma level of TNF is an independent predictor of outcome. Second, administration of purified, recombinant TNF to experimental animals will induce organ injury [43], even when given to mice which are not sensitive to the effects of endotoxin [44]. Finally, antibodies to TNF will prevent the lethality observed in septic shock in response to either lipopolysaccharide [45], or live $E$. coli $[46,47]$. Elevated levels of interleukin- 6 have also been reported in septic shock [48, 49]. Given the pivotal role of TNF in septic shock and the ability of ibuprofen to block the altered pathophysiology, it would be tempting to speculate that TNF production may be inhibited. However, since in vitro studies have shown that PGE inhibits the production of TNF [25], blocking the cyclooxygenase pathway could potentially augment cytokine production. Our data indicate that treatment with ibuprofen has virtually no effect on the production of either TNF or IL-6, although there is slightly increased production at the 3 -hr time point. Thus, the beneficial effects of cyclooxygenase inhibition are not mediated through decreased levels of TNF.

Other investigators have shown that administration of purified, recombinant TNF will activate the cyclooxygenase pathway in vivo. Kettlehut et al. [50] showed that the lethality of exogenous administered TNF could be blocked with ibuprofen, or indomethacin. Similarly, many of the pathophysiologic derangements induced with recombinant TNF could be blocked by ibuprofen
[51]. The most likely explanation for these observations is that sepsis initiates a cascade of interactions which culminate in multiorgan failure and death. In this scenario, the endotoxin from the bacteria causes TNF production in the host. This burst of TNF activity stimulates the next wave of the cascade, including products of the cyclooxygenase pathway, the prostaglandins and thromboxanes. Therefore, although neither bacteria nor TNF by themselves are directly injurious, together they synergistically perpetuate the cascade of events which leads to injury and multiorgan failure [52]. Our data support this hypothesis, since there is no diminution in the levels of TNF or IL-6, while there is an improvement in the overall status of the animals in Groups II and III.

The data regarding the endotoxin measurements are intriguing, since blocking the cyclooxygenase pathway apparently allowed for more efficient clearance of the bacteria. It is possible that inhibiting production of prostaglandins, which are immunosuppressive agents, resulted in more efficient functioning of the reticuloendothelial system, so that the bacteria were cleared more efficiently. Further studies of this area are warranted.

These data show that inhibition of the cyclooxygenase pathway results in markedly improved hemodynamics and a decrease in serum flourescent products during $E$. coli-induced septic shock. The improvements occured without any decrease in the production of TNF or IL-6 and lends further support to the hypothesis of a cytokine-induced cascade of interactions which lead to injury during the development of septic shock. Ibuprofen apparently exerts its inhibitory effects at a more distal point in this cascade.

\section{ACKNOWLEDGMENTS}

Supported in part by a grant from the American Heart Association of Michigan and National Institute of Health Grants HL39339 and GM44918.

\section{REFERENCES}

1. Simpson, P. J., and Lucchesi, B. R. Free radicals and myocardial ischemia and reperfusion injury. J. Lab. Clin. Med. 110: 13, 1987.

2. Freeman, B. A., and Crapo, J. D. Biology of disease: Free radicals and tissue injury. Lab. Invest. 47: 412, 1982.

3. McCord, J. M. Oxygen-derived free radicals in postischemic tissue injury. N. Engl. J. Med. 312: 159, 1985.

4. Emau, P., Giri, S. N., Bruss, M. L., and Shaheen-Zia. Ibuprofen prevents Pasteurella hemolytica endotoxin-induced changes in plasma prostanoids and serotonin, and fever in sheep. J. Vet. Pharmacol. Ther. 8: 352, 1985.

5. Wise, W. C., Cook, J. A., Eller, T., and Halushka, P. V. Ibuprofen improves survival from endotoxic shock in the rat. J. Pharmacol. Exp. Ther. 215: 160, 1980.

6. Kessler, E., Hughes, R. C., Denner, E. N., and Nadela, S. M. Fvidence for the presence of prostaglandin-like material in the plasma of dogs with endotoxin shock. J. Lab. Clin. Med. 81: 85, 1973. 
7. Beck, R. R., and Abel, F. L. Effect of ibuprofen on the course of canine endotoxin shock. Circ. Shock 23: 59, 1987.

8. Cook, J. A., Wise, W. C., Butler, R. R., Reines, H. D., Rambo, W., and Halushka, P. V. The potential role of thromboxane and prostacyclin in endotoxic and septic shock. Am. J. Emerg. Med. 2: $28,1982$.

9. Halushka, P. V., Reines, H. D., Barrow, S. E., Blair, I. A., Dollery, C. T., Rambo, W., Cook, J. A., and Wise, W. C. Elevated plasma 6-keto-prostaglandin $\mathrm{F}_{1}$ alpha in patients in septic shock. Cril. Care Med. 13: 451, 1985

10. Yellin, S. A., Nguyen, D., Quinn, J. V., Burchard, K. W., Crowley, J. P., and Slotman, G. J. Prostacyclin and thromboxane $A_{2}$ in septic shock: Species difference. Circ. Shock 20: 291, 1986.

11. Slotman, G. J., Quinn, J. V., Burchard, K. W., and Gann, D. S. Thromboxane, prostacyclin, and the hemodynamic effects of graded bacteremic shock. Circ. Shock 16: 395, 1985.

12. Oettinger, W., Peskar, B. A., and Beger, H. G. Profiles of endogenous prostaglandin $\mathrm{F}_{2}$ alpha, thromboxane $\mathrm{A}_{2}$ and prostacyclin with regard to cardiovascular and organ functions in early septic shock in man. Eur. Surg. Res. 19: 65, 1987.

13. Slotman, G. J., Burchard, K. W., and Williams, J. J. Interaction of prostaglandins, activated complement, and granulocytes in clinical sepsis and hypotension. Surgery 99: 744, 1986.

14. Carmona, R. H., Tsao, T. C., and Trunkey, D. D. The role of prostacyclin and thromboxane in sepsis and septic shock. Arch. Surg. 119: 189, 1984.

15. Oettinger, W. K. E., Walter, G. O., Jensen, U. M., Beyer, A., and Peskar, A. Endogenous prostaglandin $\mathrm{F}_{2}$ alpha in the hyperdynamic state of severe sepsis in man. Br. J. Surg. 70: 237, 1982.

16. Eagan, R. W., Gale, P. H., and Kuehl, F. A. Reduction of hydroperoxides in the prostaglandin biosynthetic pathway by a microsomal peroxidase. J. Biol. Chem. 254: 3295, 1974.

17. Rao, P. S., and Mueller, H. S. Lipid peroxidation and acute myocardial ischemia. Adv. Exp. Med. Biol. 161: 347, 1983.

18. Kontos, H. A., Wei, E. P., Ellis, E. F., Dietrich, W. D., and Poulishock, J. J. Prostaglandins in physiological and in certain pathological responses of the cerebral circulation. Fed. Proc. 40: 2326, 1981.

19. Pekne, G., Van Dyke, K., Peden, D., Mengoli, H., and English, D. Antioxidation theory of non-steroidal anti-inflammatory drugs based upon the inhibition of luminol enhanced chemiluminescence from the myeloperoxidase reaction. Agents Actions 12: $371,1982$.

20. Beutler, B., and Cerami, A. Tumor necrosis factor, cachexia, shock, and inflammation: A common mediator. Annu. Rev. Biochem. 57: 505, 1988.

21. Kunkel, S. L., Remick, D. G., Strieter, R. M., and Larrick, J. W. Mechanisms that regulate the production and effects of tumor necrosis factor. Cr. Rev. Immunol. 9: 93, 1989.

22. Waage, A., Halstensen, A., and Espevik, T. Association between tumor necrosis factor in serum and fatal outcome inpatients with meningococcal disease. Lancet 1: 355, 1987.

23. Berkow, R. L., Wang, D., Larrick, J. W., Dodson, R. W., and Howard, T. H. Enhancement of neutrophil superoxide production by preincubation with recombinant human tumor necrosis factor. $J$. Immunol. 139: 3783, 1987.

24. Dayer, J. M., Beutler, B., and Cerami, A. Cachectin/tumor necrosis factor stimulates collagenase and prostaglandin $\mathrm{E}_{2}$ production by human synovial cells and dermal fibroblasts. $J$. Exp. Med. 162: 2163, 1985.

25. Kunkel, S. L., Spengler, M., May, M. A., Spengler, R., Larrick, J., and Remick, D. Prostaglandin $\mathrm{E}_{2}$ regulates macrophage-der- ived tumor necrosis factor gene expression. J. Biol. Chem. 263: $5380,1988$.

26. Beamer, K. C., Daly, T., and Vargish, T. Hemodynamic evaluation of ibuprofen in canine hypovolemic shock. Circ. Shock 23: $51,1987$.

27. Jacobs, E. R., Soulsby, M. E., and Bone, R. C. Ibuprofen in canine endotoxin shock. J. Clin. Invest. 70: 536, 1982.

28. Almqvist, P. M., Keunzig, M., and Schwartz, S. I. Effect of ibuprofen in endotoxin-shocked dogs. Surg. Forum 33: 265, 1982.

29. Tahamont, M. V., and Gee, M. H. The effects of cyclooxygenase inhibition on chemiluminescence and aggregation in sheep neutrophils. Prostaglandins Leukot. Med. $24:$ 139, 1986.

30. Fletcher, J. R., and Ramwell, P. W. Modification, by asprin and indomethacin, of the haemodynamic and prostaglandin releasing effects of E. coli endotoxin in the dog. Br.J. Pharmacol. 61: 175, 1977.

31. Hinshaw, L. B., Solomon, L. A., Erdos, E. G., Reins, D. A., and Gunter, B. J. Effects of acetylsalicylic acid on the canine response to endotoxin. J. Pharmac. Exp. Ther. 157: 667, 1967.

32. Beuge, J. A., and Aust, S. D. Microsomal Lipid Peroxidation. In S. Fleischer and L. Packer (Eds.), Methods of Enzymology: Biological Oxidations, Microsomal, Cytochrome P-450, And Other $\mathrm{He}$ moprotein Systems, Academic Press, New York, 1978. Vol. 52.

33. Espevik, T., and Nissen-Meyer, J. A highly sensitive cell line, WEHI 164, clone 13 , for measuring cytotoxic factor/tumor necrosis factor from human monocytes. J. Immunol. Methods 95 : 99,1986

34. Eskandari, M. K., Nguyen, D. T., Kunkel, S. L., and Remick, D. G. WEHI 164 subclone 13 assay for TNF: Sensitivity, specificity and reliability. Immunol. Invest. 19: 69, 1990.

35. Goldstein, D. S., Feurstein, G., Izzo, J. L., Kopin, I. J., and Keiser, H. R. Validity and reliability of liquid chromatography with electrochemical detection for measuring plasma levels of norepinephrine and epinephrine in man. Life Sci. 28: 467, 1981.

36. Fitzpatrick, F. A., and Bundy, G. L. Hapten mimic elicits antibodies recognizing prostaglandin E2. Proc. Natl. Acad. Sci. USA 75: 2689,1978

37. Fitzpatrick, F. A., Gorman, R. R., McGuire, J. C., Kelley, R. C., Wynalda, M. A., and Sun, F. F. A radioimmunoassay for thromboxane B2. Anal. Biochem. 82: 1, 1977.

38. Aarden, L. A., DeGrott, E. R., Schaap, I. L., and Lansdrop, P. M. Production of hybridoma growth factor by human monocytes. Eur. J. Immunol. 17: 1411, 1987.

39. Anderson, F. L., Jubiz, W., Tsagaris, T. J., and Kuida, H. Endotoxin- induced prostaglandin $\mathrm{E}$ and $\mathrm{F}$ release in dogs. $A m$. J. Physiol. 228: 410, 1975.

40. Ball, H. A., Cook, J. A., Wise, W. C., and Halushka, P. V. Role of thromboxane, prostaglandins and leukotrienes in endotoxic and septic shock. Intensive Care Med. 12: 116, 1986.

41. Damas, P., Reuter, A., Gysen, P., Demonty, J., Lamy, M., and Franchimont, $\mathrm{P}$. Tumor necrosis factor and interleukin-1 serum levels during severe sepsis in humans. Crit. Care Med. 17: 975, 1989.

42. Debets, J. M., Kampmeijer, R., Vanderinden M. P. L., Buurman, W. A., and Vanderinden C. J. L. Plasma tumor necrosis factor and mortality in critically ill septic patients. Crit. Care Med. 17: $489,1989$.

43. Tracey, K. J., Beutler, B., Lowry, S. F., Merryweather, J., Wolpe, S., Milsark, I. W., Hariri, R. J., Fahey, T. J., Zentella, A., Albert, J. D., et al. Shock and tissue injury induced recombinant human cachectin. Science 234: 470, 1986.

44. Remick, D. G., Kunkel, R. G., Larrick, J. W., and Kunkel, S. L. 
Acute in vivo effects of human recombinant tumor necrosis factor. Lab. Invest. 56: 583, 1987.

45. Beutler, B., Milsark, I. W., and Cerami, A. C. Passive immunixation against cachectin/tumor necrosis factor protects mice from lethal effect of endotoxin. Science 229: 869, 1985.

46. Tracey, K. J., Fong, Y., Hesse, D. G., Manogue, K. R., Lee, A. T., Kuo, G. C., Lowry, S. F., and Cerami, A. Anti-cachectin/TNF monoclonal antibodies prevent septic shock during lethal bacteria. Nature 330: 662, 1987.

47. Hinshaw, L. B., Tekamp-Olson, P., Chang, A. C., Lee, P. A., Taylor, F. B. Jr., Murray, C. K., Peer, G. T., Emerson, T. E. Jr., Passey, R. B., and Kuo, G. C. Survival of primates in LD100 septic shock following therapy with antibody to tumor necrosis factor (TNF- $\alpha$ ). Circ. Shock 30: 279, 1990.

48. Waage, A., Brandtzaeg, P., Halstensen, A., Kierulf, P., and Espevik, T. The complex pattern of cytokines in serum from patients with meningococcal septic shock. Association between interleu- kin-6, interleukin-1, and fatal outcome. J. Exp. Med. 169: 333, 1989.

49. Fong, Y., Moldawer, L. L., Marano, M., Wei, H., Tatter, S. B., Clarick, R. H., Santhanam, U., Sherris, D., May, L. T., Shegal, P. B. et al. Endotoxemia elicits increased circulating $\beta$-2-IFN/ IL-6 in man. J. Immunol. 142: 2321, 1988.

50. Kettelhut, I. C., Fiers, W., and Goldberg, A. L. The toxic effects of tumor necrosis factor in vivo and their prevention by cyclooxygenase inhibitors. Proc. Natl. Acad. Sci. USA 84: 4273, 1987.

51. Talmadge, J. E., Bowersox, O., Tribble, H., Lec, S. H., Shepard, H. M., and Liggitt, D. Toxicity of tumor necrosis factor is synergistic with $\gamma$-interferon and can be reduced with cyclooxygenase inhibitors. Am. J. Pathol. 128: 410, 1987.

52. Rothestein, J. L., and Schreiber, H. Synergy between tumor necrosis factor and bacterial products causes hemorrhagic necrosis and lethal shock in normal mice. Proc. Natl. Acad. Sci. USA 85: $607,1988$. 